\title{
Development of a Liquid-Liquid Extraction Procedure for the Analysis of Amphetamine in Biological Specimens by GC-FID
}

\author{
Nikolaos Raikos*, Konstantina Spagou, Maria Vlachou, Athanasios Pouliopoulos, Elisavet Thessa- \\ lonikeos and Heleni Tsoukali
}

\author{
Laboratory of Forensic Medicine and Toxicology, Faculty of Medicine, Aristotle University of Thessaloniki, 54124 \\ Greece
}

\begin{abstract}
In the present study liquid-liquid extraction (LLE) of amphetamine from biological samples was systematically optimised. The recovery of amphetamine extraction was studied using a variety of 5 solvents (chloroform, 1-chlorobutan, dichloromethane, diethylether, ethyl acetate) as well as a system of solvents (chloroform: ethyl acetate: ethanol, 3:1:1 $\mathrm{v} / \mathrm{v})$. Furthermore the influence of the volume of the extracting solvent and the $\mathrm{pH}$ on the recovery of amphetamine was examined. The optimum conditions of LLE procedure were applied for the extraction of amphetamine from biological samples such as urine, blood and also from less commonly used biological specimens such as liver, bile, brain, vitreous humour, pericardial fluid, cerebrospinal fluid, bone marrow and bone. The determination of amphetamine was accomplished by gas chromatography equipped with a flame ionization detector (FID), after derivatization with heptafluorobutyric anhydride (HFBA).
\end{abstract}

Keywords: Amphetamine, liquid-liquid extraction, biological samples, GC-FID.

\section{INTRODUCTION}

Amphetamines are powerful central nervous system (CNS) stimulants increasing self-confidence, alertness and physical performance and have been in use since the early 1900s. They are used illegally for their psychotropic effects (euphoria and alertness) as well as doping agents in sports. Of these drugs, amphetamine and its methylenedioxylated derivatives are more commonly available in Europe and are generally abused orally.

Amphetamines have become the drug of choice for young people, and it is estimated that an average of $4.8 \%$ of young Europeans have used amphetamine for non-medical reasons at some time. The use of these substances is most common in young people from urban areas, and particularly among people spending time in clubs and dancing events [1].

Amphetamine deaths are relatively unusual compared with heroin deaths, although in some countries the number is not negligible. In Greece, no reliable information about the prevalence of the use of amphetamines is available. Up to the end of 1997 only one amphetamine related death has been published [2] and since then, seven fatal cases have been reported in which amphetamine or related derivatives have been detected [3]. Amphetamine deaths cause great concern as they usually happen suddenly among socially integrated young people. Therefore, their detection in biological fluids is important in forensic toxicology and doping control. There are numerous references describing analysis of amphetamines using a variety of extraction, derivatization

*Address correspondence to this author at the Laboratory of Forensic Medicine and Toxicology, Faculty of Medicine, Aristotle University of Thessaloniki, 54124 Greece; E-mail: raikos@med.auth.gr and instrumental methods published in the last years, demonstrating the significance of improving the analysis of amphetamines in biological samples.

Many of these procedures, though developed many years ago, are still effective and remain in wide use. Traditionally, the preparation of samples for analysis has been based on liquid-liquid extraction (LLE), the standard method in the past. Even if the last decades, the use of solid-phase extraction (SPE) for the toxicological analysis of drugs has received widespread interest and solid phase microextraction (SPME), since its invention in 1990, has been widely used in toxicological analysis. A well-defined LLE method is robust and cost effective for the extraction of amphetamines from biological samples and is still widely used in Analytical Toxicology.

LLE is a separation method based on the difference in solubility of a compound in two immiscible solvents at an appropriate $\mathrm{pH}$. LLE offers significant advantages in toxicological analysis such as preconcentration of toxic substances, simplicity, low cost, compatibility with analytical systems. LLE has also disadvantages such as the use of organic solvents which potentially produces problems to the staff's health and environmental safety, the occurrence of emulsion and time-consuming extraction steps.

A number of publications have appeared addressing extracting solvents such as diethyl ether [4, 5], ethyl acetate [6, 7], 1-chlorobutan [8,9] and various mixtures of solvents [1013] that were used in the isolation of amphetamines from biological samples by LLE, but there is no information about the recovery of amphetamines. Although there is information about the influence of the $\mathrm{pH}$ on the recovery of amphetamines in profiling of amphetamine impurities using LLE [14, 15], this has not been investigated in the extraction of amphetamines from biological samples. 
The objective of this study was the systematic optimization of amphetamine extraction from biological samples by LLE. The optimum conditions of LLE procedure were applied for the extraction of amphetamine from biological samples such as urine, blood and also from less commonly used biological samples such as liver, bile, brain, vitreous humour, pericardial fluid, cerebrospinal fluid, bone marrow and bone [16-18].

\section{MATERIALS AND METHODOLOGY}

\section{Materials}

All reagents (chloroform, ethyl acetate, chloromethane, ethanol, 1-chlorobutane, sodium hydroxide, methyl alcohol for HPLC, hydrochloric acid $37 \% \mathrm{w} / \mathrm{w}$, sulfuric acid $0.15 \mathrm{M}$ ) were of analytical grade (Merck, Darmstadt, Germany). Amphetamine was obtained from the United Nations (Office on drugs and crime) International Quality Assurance Program (IQAP) (Lipomed AG, Switzerland). A stock solution of amphetamine was prepared in methanol at a concentration $0.62 \mathrm{mg} / \mathrm{ml}$ (as free base). Heptafluorobutyric anhydride, HFBA (Alltech) was used as a derivatization reagent [19].

\section{Extraction Procedure}

Two $\mathrm{ml}$ of an aqueous sample, spiked with amphetamine at a concentration of $6.2 \mu \mathrm{g} / \mathrm{ml}$ (as free base), $2 \mathrm{ml}$ sodium hydroxide $(\mathrm{NaOH}, 1 \mathrm{M}), 5 \mathrm{ml} \mathrm{H}_{2} \mathrm{O}$ and finally $20 \mathrm{ml}$ of the solvent were added in a centrifuge tube $(50 \mathrm{ml})$. The mixture was vortexed for $10 \mathrm{~min}$ and centrifuged in low speed for 5 min. The aqueous phase was discarded and the organic filtered through a small amount of dry sodium sulfate $\left(\mathrm{Na}_{2} \mathrm{SO}_{4}\right)$ and the filter was washed with $2 \mathrm{ml}$ of the organic solvent. Then the organic layer was transferred into a clean beaker and hydrochloric acid in methanol $(10 \% \mathrm{v} / \mathrm{v} ; 50 \mu \mathrm{l})$ was added and the mixture was evaporated to dryness. The methanolic of the hydrochloric acid plays a significant role in the prevention of amphetamine loss in the evaporation stage of the procedure.

The dry residue was transferred into a $4 \mathrm{ml}$ vial and $1.5 \mathrm{ml}$ methanol was added. The mixture dried under $\mathrm{N}_{2}$. Derivatization of dry residue was followed and the sample was injected onto a GC column.

\section{Derivatization Method of Amphetamine}

The dry residue was dissolved in ethyl acetate $(100 \mu \mathrm{l})$ and HFBA $(50 \mu \mathrm{l})$ was added to the dry residue. The mixture was vortexed, incubated at $95{ }^{\circ} \mathrm{C}$ for $20 \mathrm{~min}$ and then dried and evaporated under $\mathrm{N}_{2}$ to dryness. The dry residue was then dissolved in $100 \mu \mathrm{L}$ of ethyl acetate and 1-2 $\mu \mathrm{l}$ of them were injected and analysed to GC.

\section{Gas Chromatography}

Chromatographic analysis was carried out on a CE Instruments GC 3920 B (Perkin Elmer) equipped with a flame ionization detector (FID). Separations were accomplished on a $10 \mathrm{ft}$ x $4 \mathrm{~mm} \mathrm{OV-1}$ packed column. Data were stored and analysed on a C- R6A Chromatopac integrator (Shimadzu, Kyoto, Japan). Splitless injection was used and the carrier gas was nitrogen at a flow-rate of $50 \mathrm{ml} / \mathrm{min}$. The oven temperature was $150{ }^{\circ} \mathrm{C}$. The temperatures of the injector port and the detector were set at $275^{\circ} \mathrm{C}$.

\section{RESULTS AND DISCUSSION}

\section{Linearity, Limit of Detection (LOD) and Limit of Quantitation (LOQ)}

Linearity experiments were carried out using methanolic solutions of amphetamine for the determination of recovery of the extraction procedure. A proper volume of a methanolic solution of amphetamine was placed into a glass vial (4 $\mathrm{ml}$ ). The solution was evaporated to dryness by a gentle stream of $\mathrm{N}_{2}$. The resulting dry residue was subjected to derivatization by HFBA as described above. Two replicates for each concentration were performed. The linearity $\left(y=10710 x-3253.1, R^{2}=0.9996\right)$ was found very satisfactory in the tested range $(2.6-250 \mathrm{ng} / \mu \mathrm{l})$. Limit of detection (LOD) and limit of quantitation (LOQ) were evaluated as the signalto-noise ratios of $3: 1$ and 10:1, respectively. The LOD and LOQ obtained for amphetamine were 0.8 and $2.6 \mathrm{ng} / \mu 1 \mathrm{re-}$ spectively.

\section{Selection of the Extracting Solvent}

The above extraction procedure was carried out using different solvents. Five solvents and a mixture of solvents (chloroform: ethyl acetate: ethanol, 3:1:1 v/v), which is used in our laboratory in routine analysis of nitrogen-containing basic drugs, were used in order to find out the solvent with the best mean recovery of amphetamine in spiked aqueous solutions. At least four experiments for each solvent were carried out.

Table 1 shows that higher recoveries of amphetamine were achieved using the mixture of solvents and the chloroform (the mean recoveries \pm relative standard deviation were $97 \pm 2.03$ and $93.2 \pm 2.93$ respectively).

Table 1. Results of Recovery of Amphetamine from Spiked Aqueous Samples by LLE Using Different Solvents

\begin{tabular}{|c|c|c|}
\hline Extracting Solvent & Mean Recovery (\%) & RSD (\%) \\
\hline \hline ethyl acetate & 70.4 & 1.25 \\
\hline dichloromethane & 82.4 & 4.36 \\
\hline mixture of solvents & 97 & 2.03 \\
\hline chloroform & 93.2 & 2.93 \\
\hline diethyl ether & 78.7 & 3.24 \\
\hline 1-chlorobutan & 75.4 & 6.31 \\
\hline
\end{tabular}

Therefore the mixture of solvents was further tested for the influence of the quantity of solvent and the $\mathrm{pH}$ on the recovery of amphetamine from spiked aqueous samples.

\section{Volume of the Extracting Solvent}

Various amounts of mixture of solvents were used in order to find out the optimum quantity of the extracting solvent. Specifically 5, 10 and $20 \mathrm{ml}$ of the solvents' mixture were applied to extract amphetamine from spiked aqueous samples $(6.2 \mu \mathrm{g} / \mathrm{ml}$ amphetamine concentration, as free base). Four experiments were carried out for each volume of the solvent.

Table 2 shows that the mean recovery of amphetamine was approximately the same (94.5 \pm 0.61 and $97 \pm 2.03)$, when 
10 and $20 \mathrm{ml}$ of solvent were used. When $5 \mathrm{ml}$ of the extracting solvent was used, the recovery $(79.7 \pm 7.75)$ and the relative standard deviation (RSD) were decreased. Hence the volume of $20 \mathrm{ml}$ was selected for the rest of the study.

Table 2. Results of Recovery of Amphetamine from Spiked Aqueous Samples by LLE Using Different Volumes of the Mixture of Solvents

\begin{tabular}{|c|c|c|}
\hline $\begin{array}{c}\text { Quantity of Extract- } \\
\text { ing Solvent }(\mathbf{m l})\end{array}$ & $\begin{array}{c}\text { Mean Recovery } \\
(\boldsymbol{\%})\end{array}$ & RSD (\%) \\
\hline \hline 5 & 79.7 & 6.17 \\
\hline 10 & 94.5 & 0.61 \\
\hline 20 & 97 & 2.03 \\
\hline
\end{tabular}

\section{Selection of Proper pH of the Sample}

The $\mathrm{pH}$ value of the biological sample affects the recovery of amphetamines using liquid -liquid extraction. Aqueous samples, spiked with amphetamine at a concentration of $6.2 \mu \mathrm{g} / \mathrm{ml}$ (as free base), were extracted using $20 \mathrm{ml}$ of the tested mixture of solvents at $\mathrm{pH} \mathrm{7,8,9}$ and 10. Two experiments were carried out for each $\mathrm{pH}$ value.

Table 3 shows an increase of recovery of amphetamine having the greater value of 97.2 at $\mathrm{pH}=10$. At the previous experiments for the selection of the proper volume of the extraction solvent (see Table 2) the $\mathrm{pH}$ of the final solution, ( $2 \mathrm{ml}$ aqueous solution of amphetamine, $5 \mathrm{ml} \mathrm{H}_{2} \mathrm{O}$ and $2 \mathrm{ml}$ $\mathrm{NaOH} 1 \mathrm{M}$ ) was 13 and the recovery of amphetamine was $97 \pm 2.03$. It is obvious that the recovery of amphetamine is identical by increasing the $\mathrm{pH}$ from 10 to 13 .

Table 3. Recovery of Amphetamine Using Liquid-Liquid Extraction from Spiked Aqueous Samples at Various pH Values

\begin{tabular}{|c|c|}
\hline $\mathbf{p H}$ & Recovery (\%) \\
\hline \hline 7 & 64.4 \\
\hline 8 & 76.7 \\
\hline 9 & 83.9 \\
\hline 10 & 97.2 \\
\hline
\end{tabular}

These experiment results are reasonable and expected because amphetamine is a basic drug with pKa value of 9.9. The amino-group of the molecule of amphetamine is neutralized by raising the $\mathrm{pH}$ at values greater than 10 and so the amphetamine is less soluble in aqueous phase of the biological specimen and highly soluble in organic solvents and is easily extracted. So a $\mathrm{pH}$ equal or greater than 10 is suggested for the liquid -liquid extraction of amphetamine.

\section{Isolation of Amphetamine from Biological Specimens with Liquid-Liquid Extraction}

\section{Biological Samples}

Urine, blood, liver, bile, brain, vitreous humour, pericardial fluid, cerebrospinal fluid, bone and bone marrow were obtained from post-mortem specimens that had been screened negative for drugs of abuse by thin layer chroma- tography, fluorescence polarization immunoassay and gas chromatography.

\section{Pre-Treatment of Biological Samples}

Blood, urine, bile, pericardial fluid, cerebrospinal fluid and vitreous humour were used without any pre-treatment. The other specimens were pre-treated as follow:

Liver: One gram of liver specimen was mixed with $2 \mathrm{ml}$ distilled $\mathrm{H}_{2} \mathrm{O}$ and finely minced.

Brain-Bone marrow: Two $\mathrm{ml}$ of $2.5 \mathrm{~N} \mathrm{NaOH}$ was added to one gram of tissue. The mixture was sonicated for $15 \mathrm{~min}$, vortexed and transferred to a refrigerator $\left(4^{\circ} \mathrm{C}\right)$ until the lipid content to be frozen and then the fatty content was discarded.

Bone: Bone pieces were cleaned from muscle tissues and pulverized in a mortar. Ten $\mathrm{ml}$ of $3 \mathrm{~N} \mathrm{HNO}_{3}$ was added to $1 \mathrm{~g}$ of bone powder. Then the mixture was demineralised at room temperature for $24 \mathrm{~h}$. After demineralising the $\mathrm{pH}$ was adjusted to 10 . Then, it was vortexed and filtered. The filtrate was concentrated to few $\mathrm{ml}$ of a yellowish clear solution [18].

\section{Extraction Procedure}

The optimum conditions from the above experimental procedure were applied for the extraction of the amphetamine from different biological specimens. The blank biological samples were spiked with amphetamine at a concentration of $6.2 \mu \mathrm{g} / \mathrm{ml}$ (as free base). For the specimens which pre-treatment was necessary, a certain volume of the stock solution of amphetamine was added before the pre-treatment procedure so as the final concentration to be $6.2 \mu \mathrm{g} / \mathrm{ml}$ (as free base). Then $5 \mathrm{ml} \mathrm{H} \mathrm{H}_{2} \mathrm{O}$ and $2 \mathrm{ml} \mathrm{NaOH}$ were added in 2 $\mathrm{ml}$ of the spiked sample. In brain and bone marrow the solution of $\mathrm{NaOH}$ was not added, because the final solution after the pre-treatment procedure was already alkaline. The spiked biological samples were extracted with the optimal conditions as referred below:

Sample volume: $2 \mathrm{ml}, \mathrm{pH}$ of sample: 10 or more, addition of: $2 \mathrm{ml} \mathrm{NaOH} 1 \mathrm{M}$ and $5 \mathrm{ml} \mathrm{H}_{2} \mathrm{O}$, extraction solvent: mixture of solvents (chloroform: ethyl acetate: ethanol, 3:1:1 $\mathrm{v} / \mathrm{v})$, volume of the extraction solvent: $20 \mathrm{ml}$.

After the evaporation of methanol, in the final stage of the extraction procedure, sufficient amount of dry residue remained in the beaker. This excess of the residue caused troubles with the derivatization with HFBA (very low reaction yield). To overcome this low reaction yield of the derivatization reaction a further purification of the initial extract was made by back extracting the amphetamine into an aqueous solvent. This was achieved with a $\mathrm{H}_{2} \mathrm{SO}_{4}(0.15 \mathrm{M})$ solution that causes the amine group of amphetamine to become positively charged thus making it more soluble in the aqueous phase. Neutral compounds remain in the organic phase and are discarded thus cleaning up the initial extract. The amphetamine is then extracted from the aqueous phase by adjusting the $\mathrm{pH}$ at values equal or greater than 10 and extracting into the organic phase.The cleaning procedure was as follows:

The initial extract was evaporated to approximately $5 \mathrm{ml}$ final volume. Then it was placed into a $50 \mathrm{~mL}$ polyethelene centrifuge vial and $3 \mathrm{ml}$ of $\mathrm{H}_{2} \mathrm{SO}_{4}(0.15 \mathrm{M})$ was added in the vial. The mixture was strongly vortexed $(5 \mathrm{~min})$ and centri- 
Table 4. Recovery of Amphetamine from Various Spiked Biological Samples

\begin{tabular}{|c|c|c|c|c|}
\hline Specimen & No. of Analyses & Range of Recoveries (\%) & Mean Recovery (\%) & $\operatorname{RSD}(\%)$ \\
\hline Blood & 4 & $78.9-87.2$ & 82.9 & 4.29 \\
\hline Liver & 4 & $75.5-88.0$ & 80.3 & 6.92 \\
\hline Bile & 4 & $81.0-86.5$ & 83.6 & 3.04 \\
\hline Brain & 4 & $74.4-82.8$ & 79.2 & 4.65 \\
\hline Pericardial fluid & 4 & $73.6-88.4$ & 81.2 & 8.77 \\
\hline Cerebrospinal fluid & 4 & $82.7-88.2$ & 85.2 & 2.66 \\
\hline Bone marrow & 4 & 68.9-83.9 & 76.9 & 8.91 \\
\hline Bone & 4 & $84.4-90.6$ & 88 & 3.09 \\
\hline
\end{tabular}

fuged in low speed ( $2 \mathrm{~min}$ ). The organic phase was then rejected and $2 \mathrm{ml}$ of $\mathrm{NaOH}(1 \mathrm{M})$ and $10 \mathrm{ml}$ of the mixture of the solvents were added into the acidic aqueous layer. The mixture was vortexed $(5 \mathrm{~min})$ and centrifuged in low speed ( $2 \mathrm{~min}$ ) and finally the organic phase was evaporated to dryness, after the addition of $50 \mu \mathrm{L}$ methanolic solution of $\mathrm{HCl}$ $(10 \% \mathrm{v} / \mathrm{v})$. The dry residue was reconstituted in methanol and transferred quantitatively into a $4 \mathrm{ml}$ vial. Subsequently, methanol dried under a stream of nitrogen.

The final dry residue was derivatized with HFBA and analyzed in GC. The whole extraction procedure with the cleaning-up stage had been applied also in spiked water solutions of amphetamine. The achieved recovery was identical of that got from the extraction procedure without the back extraction step.

Hence, urine, blood, liver, pericardial fluid, vitreous humor, cerebrospinal fluid, bile bone, bone marrow and brain specimens spiked with amphetamine were extracted with the optimal conditions and the back extraction stage additionally. Each biological sample extracted and analyzed four times and the results are shown in Table 4.

\section{CONCLUSION}

The findings of this study demonstrate that chloroform and the system of solvents containing chloroform gave higher recoveries in comparison with the other tested solvents and the biological samples require a further cleaning procedure thus the derivatization reaction with HFBA of the final extract to have a high yield. The developed extraction method of the amphetamine from biological specimens, despite the additional back extraction step, provides satisfactory recoveries and good repeatability, is simpler in its functioning comparing to other sample preparation techniques such as solid phase extraction (SPE) that requires particular apparatus and has low cost.
Conclusively, the proposed extraction method is suitable for the isolation of amphetamine from biological samples in routine toxicological analysis.

\section{REFERENCES}

[1] European Monitoring Centre for Drugs and Drug Addiction, 2006: The State of The Drugs Problem In Europe. http://ar2006.emcdda.europa.eu (Oct. 2008)

[2] Tsatsakis, A.M.; Michalodimitrakis, M.N.; Patsalis, A.N. Vet. Hum. Toxicol., 1997, 39(4), 241-4.

[3] Raikos, N.; Tsoukali, H.; Psaroulis, D.; Vassiliadis, N.; Tsoungas, M.; Njau, S.N. Forensic Sci. Int., 2002, 128(1-2), 31-34.

[4] Marquet, P.; Lacassle, E.; Battu, C.; Faubert, H.; Lachatre, G. J. Chromatogr. B, 1997, 700, 77-82.

[5] Concheiro, M.; Maria, S.; Simoes, S.; Quintela, O.; Castro, A.; Rodrigues, M.J.D.; Cruz, A.; Lopez-Rivadulla, M. Forensic Sci. Int., 2007, 171, 44-51.

[6] Sato, M.; Mitsui, T. J. Pharmaceut. Biomed., 1997, 16, 139-145.

[7] Kuwayama, K.; Inoue, H.; Kanamori, T.; Tsujikawa, K.; Miyaguchi, H.; Iwata, Y.; Kamo, N.; Kishi, T. Forensic Sci. Int., 2007, 171, 9-15.

[8] Geiser, L.; Cherkaoui, S.; Veuthey, J.L. J. Chromatogr. A, 2000, 895, 111-121.

[9] Drummer, O.H.; Gerostamoulos, D.; Chu, M.; Swann, P.; Boorman, M.; Cairns, I. Forensic Sci. Int., 2007, 170, 105-110.

[10] Wang, C.; Fan, G.; Lin, M.; Chena, Y.; Zhaoa, W.; Wu, Y. J. Chromatogr. B, 2007, 854, 48-56.

[11] Pizzolato, T.M.; Lopez de Alda, M.J.; Barcelo, D. Trends Anal. Chem., 2007, 26(6), 609-624.

[12] Saito, T.; Mase, H.; Takeichi, S.; Inokuchi, S. J. Pharm. Biomed 2007, 43, 358-363.

[13] Weinmann, W.; Bohnert, M. Forensic Sci. Int., 1998, 91(2), 91-10.

[14] Andersson, K.; Jalava, K.; Lock, E.; Huizer, H.; Kaa, E.; Lopes, A.; Poortman-van der Meer, A.; Cole, M.D.; Dahle, J.; Sippola, E. Forensic Sci. Int., 2007, 169, 64-76.

[15] Jonson, C.S.L.; Artizzu, N. Forensic Sci. Int., 1997, 93, 99-116.

[16] Ensslin, K.H.; Kovar K.A.; Maurer, H.H. J. Chromatogr. B, 1996, 683, 189-197.

[17] Narasimhachari, N.; Friedel, R.O. J. Chromatogr., 1979, 164, 386393.

[18] Raikos, N.; Tsoukali, H.; Njau, S. Forensic Sci. Int., 2001, 123 , 140-141.

[19] Manuals for use by national laboratories, ST/NAR/27, Recommended methods for the detection and assay of heroin, cannabinoids, cocaine, amphetamine, methamphetamine and ring-substituted amphetamine derivatives in biological specimens; United Nations, 1995. 